\title{
Correction to: Systems Engineering
}

\author{
Correction to: \\ R. Haberfellner et al., Systems Engineering, \\ https://doi.org/10.1007/978-3-030-13431-0
}

The original version of this book has been revised since this book was inadvertently published with few errors.

Chapter 1

Page 25 questions appear as

9. Explain the difference between a complex and a complicated system.

10. What are the three main points of view that can be used to create a system model?

11. Choose a system based on an arbitrary example for further investigation:

- Structure the system hierarchically!

- Which system aspects would be interesting?

it should re-order to

9. Choose a system based on an arbitrary example for further investigation:

- Structure the system hierarchically!

- Which system aspects would be interesting?

10. Explain the difference between a complex and a complicated system.

11. What are the three main points of view that can be used to create a system model?

The updated online version of the book can be found at https://doi.org/10.1007/978-3-030-13431-0 


\section{Chapter 2}

Page 97 question 20 should be deleted

Chapter 9 and 16

Red text in the figures and tables should appear in black text

Self-Check of Knowledge and Understanding

\section{Chapter 1}

Page 417 Question 1 says:

What is meant by systems engineering systems thinking?

it should say

What does systems engineering systems thinking consist of?

Page 417 Question 3 says:

In which cases is it not appropriate to use the term "System"?

it should say

In which cases is it not appropriate to use the term "system"?

Page 418 Question 4 says:

Sketch an example of a system with its components and their relationships that is imbedded in an environment and interacting with other systems.

it should say

Sketch a system with its components and their relationships that is embedded in an environment and interacts with other systems.

Page 418 Question 5 says:

What is a "system of systems" (SoS)? What is the main difference between a subsystem and an SoS?

it should say

What is the main difference between a system consisting of subsystems and one consisting of systems $(\mathrm{SoS})$ ?

Page 418 Question 7 says:

What is meant by "black, grey and white box" models for describing real-world phenomena?

it should say 
What is meant by "black-, gray-, and white-box" models for describing real-world phenomena?

\section{Chapter 2}

Page 420 Question 2 says:

What are the components (basic principles) of the systems engineering process model?

it should say

What are the four components (basic principles) of the systems engineering process model?

Page 420 Question 3 says:

What do the individual components of the systems engineering process model focus on?

it should say

What are the individual components focusing on?

Page 421 Question 6 says:

Is it necessary to pass through all project phases?

it should say

Is it necessary to pass all project phases?

Page 421 Question 7 says:

The term "analysis" is embodied twice in the problem-solving cycle. What is meant in one case and in the other case?

it should say

The term "analysis" is embodied twice in the PSC. What is meant in each case?

Page 421 Question 8 says:

What is the difference between the analysis and evaluation of solutions steps?

it should say

What is the difference between the steps analysis and evaluation of solutions?

Page 421 Question 9 says:

What is the difference between actual-state-oriented and desired-state-oriented process models? How or where would you position the systems engineering process model? 
it should say

What is the difference between actual-state-oriented and desired-state-oriented process models? How or where would you position the Hall/BWI process model?

Page 421 Question 10 says:

What role does the client have in the problem-solving cycle?

it should say

What role does the client play in the PSC?

Page 422 Question 12 says:

What is meant by the term "Vee model"? What are its characteristics? To which component of the systems engineering process model does it relate?

it should say

What is meant by the term "V-Model"? What are its characteristics?

Page 422 Question 14 says:

What is denoted by the term "simultaneous (concurrent) engineering"?

it should say

What does the term "simultaneous (concurrent) engineering" denote?

Page 422 Question 15 says:

What are the characteristics of the so-called "agile process models"? Give some examples of that category.

it should say

What are the characteristics of the so=called "Agile Process Models"? Give some important examples of that category.

Page 422 Question 17 says:

Can you find some agile properties in the systems engineering model in spite of its primarily plan-driven character?

it should say

Can you find some agile properties in our systems engineering model in spite of its primarily plan-driven character?

Chapter 3

Page 423 Question 3 says:

What do we mean by saying that systems thinking may be applied to a problem in addition to the solutions? 
it should say

What do we mean by saying that systems thinking may be applied to a problem and to the solutions?

Page 424 Question 7 says:

Do you think it is possible that the admissible ignorance tends to zero over the course of the project?

it should say

Do you think it is possible that the admissible ignorance tends toward zero over the course of the project?

Page 424 Question 9 says:

Are immediate measures in contrast to a systematic systems engineeringapproach?

it should say

Are immediate measures in contrast to a systematic systems engineering approach?

Page 424 Question 10 says:

Explain the different thinking levels in problem-solving.

it should say

Explain the different thinking levels of problem-solving with the help of Fig. 3.10.

Page 424 Question 11 says:

What kind of information is acquired in the single steps of the problem-solving cycle and is passed over to the next steps?

it should say

What kind of information is acquired in the single steps of the PSC and is passed over to the next steps?

Chapter 4

Page 426 Question 4 says:

Explain the term project management.

it should say

Explain the term "project management."

Page 426 Question 7 says:

Which tasks are summarized under the term project management? 
it should say

Which tasks are summarized under the term "project management"?

Page 426 Question 9 says:

Which ideal typical forms of project organization (PO) do you know?

it should say

Which ideal typical forms of project organization do you know?

Page 426 Question 10 says:

What are the characteristics, the advantages, and disadvantages of these PO forms?

it should say

What are the characteristics, the advantages, and disadvantages of these forms of project organization?

Page 426 Question 11 says:

What kind of project organization seems to suitable for which kind of projects?

it should say

Which type of project organization is suitable for which type of project?

Page 426 Question 12 says:

Which methods, techniques, tools for planning and control of projects do you know?

it should say

Which methods, techniques, tools for planning, and control of projects do you know?

Page 427 Question 13 says:

What are typical demands on a project manager? From the management perspective, from the perspective of the team members, etc.?

it should say

What are typical demands of a project manager? From the management perspective, from the perspective of the team members, etc.?

Page 427 Question 14 says:

What are typical attributes of high performing teams?

it should say

What are typical attributes of a high performing team?

Page 427 Question 15 says: 
What are the consequences of the increasing use of agile methods for the systems engineering concept? Which modules will continue to apply and which one will be most affected?

it should say

In which direction may project management evolve in response to the emergence of agile methods?

\section{Chapter 5}

Page 427 Question 1 says:

How would you define the term "structure of a system"?

it should say

How would you define the term "structure" of a system?

Page 427 Question 2 says:

How would you define the term architecture?

it should say

How would you define the term "architecture"?

Page 427 Question 3 says:

Give examples for architectural variants

it should say

Give your own examples of architectural variants

Page 427 Question 7 says:

Sketch the model of Henderson/Clark for architectural innovations in the context with other innovations.

it should say

Sketch the Henderson/Clark model for architectural innovations in the context of other innovations.

Chapter 6.1

Page 428 Question 3 says:

How are detected weaknesses or failures, conceivable causes and measures to resolve the problems mentally and logically interconnected?

it should say

How are detected weaknesses or failures, conceivable causes, and measures to resolve the problems mentally and logically interconnected? 
Page 429 Question 6 says:

What techniques and tools do you know for situation analysis?

it should say

Which techniques and tools do you know about for situation analysis?

Page 429 Question 7 says:

Does it make sense to use a working hypothesis in the situation analysis? Does this not rather mean that one works with prejudices?

it should say

Does it make sense to use a working hypothesis in the situation analysis? Does this not mean that one works with prejudices?

Chapter 6.2

Page 429 Question 2 says:

How are the steps "formulation of objectives," "situation analysis," "synthesis/analysis," "evaluation connected" linked together?

it should say

How are the steps "formulation of objectives," "situation analysis," "synthesis/analysis," and "evaluation" connected, linked together?

Page 429 Question 3 says:

Why don't compulsory objectives play a role in the evaluation step?

it should say

Why do compulsory objectives not play a role in the "evaluation" step?

Page 430 Question 6 says:

Can certain demands be objectives and means?

it should say

Can certain demands be objectives in addition to means?

Page 430 Question 7 says:

Does it make sense to use the term "objective" goals or "objective" targets or aims or objectives? (Here: objective as the opposite of subjective).

it should say

Does it make sense to use the term "objective" (here: objective as the opposite of subjective) goal/target/aim/?

Page 430 Question 9 says: 
How can we attribute different significance to objectives?

it should say

How can we give different importance to objectives?

Page 430 Question 10 says:

What can one do, if goals oppose or contradict each other? Give examples.

it should say

What can one do if goals oppose or contradict each other? Give examples.

Chapter 6.3

Page 431 Question 1 says:

What does synthesis mean; what does analysis mean?

it should say

What does synthesis mean? What does analysis mean?

Page 431 Question 3 says:

Explain Fig. 6.17 relating to the idea of abstraction and concretization

it should say

Explain Fig. 6.15 relating to the idea of abstraction and concretization

Page 431 Question 7 says:

What is the logic to differentiate between an intuitive and a formal analysis?

it should say

What is the logic in differentiating between an intuitive and a formal analysis?

Chapter 6.4

Page 432 Question 1 says:

Which steps in the problem-solving cycle are the main information suppliers for the evaluation?

it should say

Which steps in the PLC are the main information suppliers for the evaluation

Page 432 Question 4 says:

Which methods for comparative assessment do you know?

it should say

Which methods of comparative assessment do you know? 
Page 432 Question 6 says:

Why does it make sense to draw the course of a utility function in a graphic representation?

it should say

Why does it make sense to represent the course of a utility function on a graph?

Page 433 Question 10 says:

Is it possible that the decision-making body deviates from the proposal of the project group?

it should say

Is it possible for the decision-making body to deviate from the proposal of the project group?

\section{Chapter 6.5}

Page 433 Question 1 says:

Do you know any other special cases you would find worth discussing? The authors would like to hear your views.

it should say

Do you know any other special cases you would find worth discussing? The authors would like to know your views.

\section{Chapter 7}

Page 434 Question 1 says:

Name some basic principles concerning (i) the application of the systems approach, (ii) the application of an accepted action model, and (iii) the application of methods, techniques, tools.

it should say

- Do you agree on the basics summarized in this chapter? Or are there too few, too many or the wrong ones?

- The authors would like to receive feedback.

\section{Chapter 8}

Page 434 Question 1 says:

Can you find the abovementioned basics in the case study? see (Chap. 7).

it should say

Can you find the aforementioned basics in the case study? 
Chapter 9

Page 434 Question 1 says:

Can you find the abovementioned basics in the case study? see (Chap. 7).

it should say

Can you find the above-mentioned basics in the case study?

\section{Chapter 11}

Page 434 Question 1 says:

Do you agree with the recommendations?

it should say

Do you agree to the recommendations

Page 434 Question 2 says:

Would you modify, extend, or reduce the list? The authors would like you to share your judgment with them.

it should say

Would you modify, extend or reduce the list? The authors would like to hear about your judgment.

Chapter 12

Page 434 Question 1 says:

Does the list presented in Fig. 11.1 reflect your experience? Do the arguments apply to it?

it should say

Does the list presented in Table 12.1 reflect your experience? Do the arguments apply to it?

Chapter 15

Page 435 question 3 should be included

3. What are you missing and why? 